\title{
Calixto Machado: Brain Death a Reappraisal
}

\author{
Springer, NY, 2007, \$119, ISBN 978-0-387-38975-2
}

\author{
Eelco F. M. Wijdicks
}

Published online: 12 March 2009

(c) Humana Press Inc. 2009

Dr Machado is prominently known for organizing International Symposia on Coma and Death in Havana, Cuba. This book has some overlap with earlier published proceedings of the 2004 meeting, but concentrates on Brain Death. Although the book is more theoretical than practical, it may interest neurointensivists.

The monograph starts with a chapter explaining that "the concept of brain death did not evolve to benefit organ donation" followed by a chapter describing the first transplant from a brain death donor. This is an interesting historical period that has not been sufficiently researched before. Other chapters include "conceptional approach to human death on neurologic grounds", chapters on the clinical diagnosis of brain death and ancillary tests but also ventures into other states of coma including persistent vegetative state and minimally conscious state. The clinical examination of brain death is described in detail including the recognition of pitfalls.

The book leans heavily on work by earlier scholars, but it includes some original work. There is a comprehensive chapter on ancillary tests.
A brief legal chapter concludes the book, but unfortunately is curtailed to the Cuban Law for the determination of brain death. The book provides good insights in competing perspectives. I do not know what it is but brain death fascinates many physicians, ethicists and many other thinkers. It is unknown how many experts-cited by machado-are involved with all aspects of braindeath determination and the challenges of organ donation.

The title prompted me to look for a reappraisal but what Machado has essentially done is adroitly providing a summary of the evolution of ideas in understanding comatose states including brain death. It is not clear to me after reading his book, whether he sometimes feels the urge to hop on the controversy bandwagon. As Machado sees it "the physician will still need to face a thorny clinical state created by a nonfunctioning brain and a preserved heart beat". To me that is a stretch.

This book is marshaling a wealth of facts and Machado appreciates all the nuances but its reconstruction of the topic is uneven and it lacks a new fresh look at the subject matter.

E. F. M. Wijdicks ( $\square)$

Mayo Clinic, Rochester, MN, USA

e-mail: wijde@mayo.edu 